\title{
A case report of Talaromyces marneffei Oro- pharyngo-laryngitis: a rare manifestation of Talaromycosis
}

\author{
Thanyarak Wongkamhla', Piriyaporn Chongtrakool ${ }^{2}$ and Anupop Jitmuang ${ }^{1 *}$ (D)
}

\begin{abstract}
Background: The incidence of Taralomyces marneffei infection in HIV-infected individuals has been decreasing, whereas its rate is rising among non-HIV immunodeficient persons, particularly patients with anti-interferon-gamma autoantibodies. T. marneffei usually causes invasive and disseminated infections, including fungemia. T. marneffei oro-pharyngo-laryngitis is an unusual manifestation of talaromycosis.

Case presentation: A 52-year-old Thai woman had been diagnosed anti-IFNy autoantibodies for 4 years. She had a sore throat, odynophagia, and hoarseness for 3 weeks. She also had febrile symptoms and lost $5 \mathrm{~kg}$ in weight. Physical examination revealed marked swelling and hyperemia of both sides of the tonsils, the uvula and palatal arches including a swelling of the epiglottis, and arytenoid. The right tonsillar biopsy exhibited a few intracellular oval and elongated yeast-like organisms with some central transverse septum seen, which subsequently grew a few colonies of T. marneffei on fungal cultures. The patient received amphotericin B deoxycholate $45 \mathrm{mg} /$ dayfor 1 weeks, followed by oral itraconazole $400 \mathrm{mg} /$ day for several months. Her symptoms completely resolved without complication.
\end{abstract}

Conclusion: In patients with anti-IFN- $\gamma$ autoantibodies, T. marneffei can rarely cause a local infection involving oropharynx and larynx. Fungal culture and pathological examination are warranted for diagnosis T. marneffei oropharyngo-laryngitis. This condition requires a long term antifungal therapy.

Keywords: Taralomyces marneffei, Talaromycosis, Oro-pharyngo-laryngitis, Anti-interferon-gamma autoantibodies

\section{Background}

Talaromyces marneffei (formerly known as Penicillium marneffei) is an important dimorphic fungus; it is the only member in the genus causing systemic mycosis and is more prevalent in Southeast Asia [1-3]. Historically, human T. marneffei infection has been confined to patients with acquired immunodeficiency syndrome (AIDS) [1]. In recent years, the incidence of T. marneffei infection in those populations has been decreasing following treatment with highly active antiretroviral regimens and preventive measurements. However, the rate of this infection in non-HIV-infected individuals has been rising, particularly in patients with anti-interferon-

\footnotetext{
* Correspondence: anupopmix@yahoo.co.th

${ }^{1}$ Division of Infectious Diseases and Tropical Medicine, Department of

Medicine, Faculty of Medicine Siriraj Hospital, Mahidol University, 2 Wanglang

Road, Bangkoknoi, Bangkok 10700, Thailand

Full list of author information is available at the end of the article
}

gamma autoantibodies (anti-IFNy autoantibodies), patients receiving systemic corticosteroids or immunosuppressive agents, organ transplant recipients, and patients receiving novel anti-cancer targeted therapies [4]. When T. marneffei infects those populations, it usually causes fungemia and disseminated disease to various organs, such as the skin, lymph node, lung, spleen, and bone $[4,5]$.

Oro-pharyngo-laryngitis caused by T. marneffei is a very uncommon talaromycosis, and has been rarely reported, with previous case reports of T. marneffei oropharyngitis and pharyngo-laryngitis limited to patients with underlying AIDS [6-8]. Herein, we report a rare manifestation of talaromycosis in a woman who had underlying anti-IFNy autoantibodies. She presented with subacute oro-pharyngo-laryngitis, which was rapidly resolved following a systemic antifungal therapy.

(c) The Author(s). 2019 Open Access This article is distributed under the terms of the Creative Commons Attribution 4.0 International License (http://creativecommons.org/licenses/by/4.0/), which permits unrestricted use, distribution, and reproduction in any medium, provided you give appropriate credit to the original author(s) and the source, provide a link to the Creative Commons license, and indicate if changes were made. The Creative Commons Public Domain Dedication waiver (http://creativecommons.org/publicdomain/zero/1.0/) applies to the data made available in this article, unless otherwise stated. 
(This work was presented in part at the 9th Trends in Medical Mycology (TIMM) Meeting, October 11-14, 2019 in Nice, France)

\section{Case presentation}

A 52-year-old Thai woman had been diagnosed antiIFNy autoantibodies for 4 years. Four years ago (March 2015), she presented with prolonged fever, a weight loss of approximately $10 \mathrm{~kg}$, bilateral tonsillar enlargement, and multiple cervical lymphadenopathy. A lymph node biopsy from the left cervical node showed the growth of Mycobacterium absessus. Disseminated Mycobacterium abscessus infection was diagnosed. She denied using illicit drugs, herbal medicines, or corticosteroids. Immunological studies, including anti-HIV testing, were all negative, but anti-IFNy autoantibodies tested highly positive. She received intravenous imipenem and amikacin for a primary anti-mycobacterial therapy, which were later switched to oral clarithromycin and ciprofloxacin for maintenance therapy. She had relapse infections twice during the course of treatment. Thereafter, the anti-mycobacterial regimen was changed to oral clarithromycin and linezolid. Following the new regimen, she complied well with the treatment, and her condition was in remission for 1 year. Before this admission, she had a sore throat, which was particularly more painful at the right side of the pharynx, odynophagia, and hoarseness for 3 weeks. She also had febrile symptoms and lost $5 \mathrm{~kg}$ in weight. She received oral amoxicillin $1.5 \mathrm{~g} /$ day from a primary physician, but her symptoms did not resolve. She denied foreign body sensation, and had no dysphagia, stridor, or difficult breathing. Physical examination revealed marked swelling and hyperemia of both sides of the tonsils, including the uvula and palatal arches (Fig. 1), and a single left submandibular lymph node, sized approximately $1 \mathrm{~cm}$, was identified. Indirect laryngoscopy demonstrated a

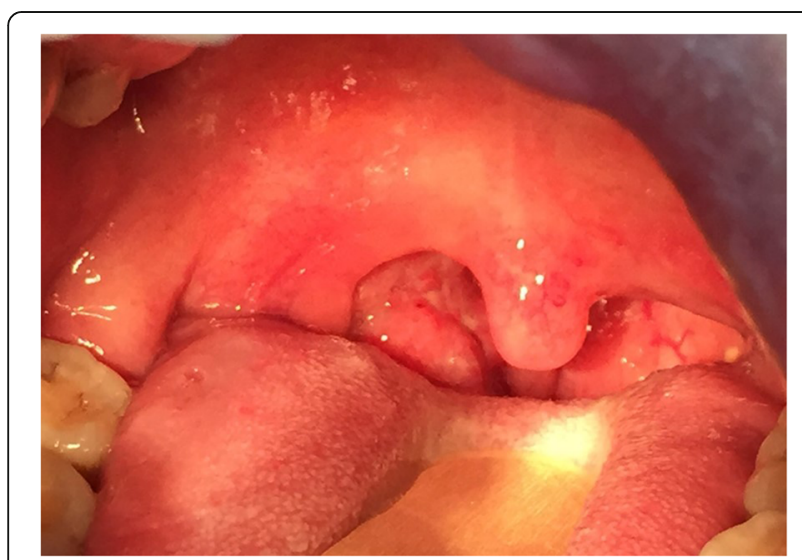

Fig. 1 Physical examination revealed marked swelling and hyperemia of both sides of the tonsils, including the uvula and palatal arches moderate swelling of the epiglottis, arytenoid, and vocal cord with normal airway opening. There were no skin papules or nodules, including no hepatosplenomegaly found. Blood chemistries, including plain chest radiography, were unremarkable. The patient was performed right tonsillar biopsy at 1 day following admission. The tissue biopsy Gram stain (Fig. 2a), including the pathological sections, exhibited a few intracellular oval and elongated yeast-like organisms with some central transverse septum seen with dense small lymphoid cell and plasma cell infiltrates. Acid fast and modified acid fast staining from the pathological sections were negative. One week later, the tissue biopsy grew few mold colonies with the typical diffusible red-colored pigment on the fungal cultures (Fig. 2b). Morphological identification based on lactophenol cotton blue microscopic examination demonstrated these to be hyaline septate molds, with branched and non-branched conidiophores consisting of brush-like phialides with long chains of round and elliptical conidia (Fig. 2c). All of the findings were suggestive of T. marneffei. However, antifungal susceptibility testing was not performed due to there being no standard breakpoint criteria for interpretation. The tissue sent for bacterial and mycobacterial culture showed no significant growth. Routine blood cultures (BD BACTEC ${ }^{\mathrm{mm}}$, Becton, Dickinson and Company), including fungal and mycobacterial blood cultures (BD BACTEC ${ }^{\mathrm{mm}}$ Myco/F Lytic, Becton, Dickinson and Company) were negative for any microorganisms. Thus, no evidence of relapsed mycobacterial disease or other pathogen co-infections was detected.

Following the diagnosis of $T$. marneffei infection, amphotericin B deoxycholate $45 \mathrm{mg} /$ day $(0.6 \mathrm{mg} / \mathrm{kg} /$ day $)$ was commenced as the primary antifungal therapy. The patient continued receiving oral clarithromycin and linezolid for $M$. abscessus maintenance therapy. Following 5 days of amphotericin therapy, the patient developed acute kidney injury with a rising creatinine level from 0.86 . to $2.44 \mathrm{mg} / \mathrm{dL}$. Her blood potassium, magnesium, and bicarbonate levels were $3.4,1.7$, and $24 \mathrm{mEq} / \mathrm{L}$, respectively. Finally, the antifungal regimen was changed to itraconazole oral solution with a daily dose of 400 $\mathrm{mg} /$ day after receiving amphotericin $\mathrm{B}$ for 5 days. The presenting symptoms of a sore throat and odynophagia disappeared after 1 week of the antifungal therapy. Four weeks after the treatment, the swelling of the pharynx and larynx were markedly reduced. She was continued with itraconazole for 4 months, and later a dose of 200 $\mathrm{mg} /$ day was used for long-term secondary prophylaxis. Her symptoms completely resolved with no complication. She still has been receiving the itraconazole prophylaxis until now.

\section{Discussion}

T. marneffei infection is an opportunistic fungal infection that is increasingly reported among non-HIV 


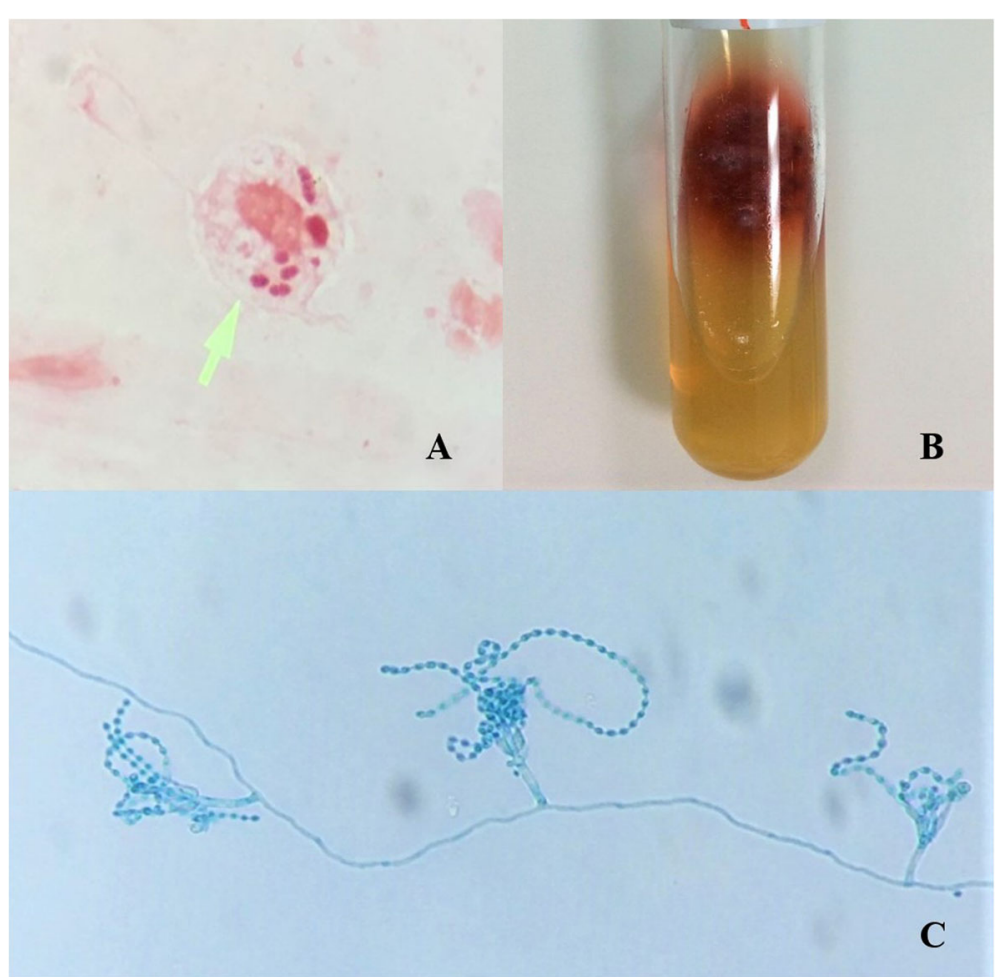

Fig. 2 a Tissue Gram stain from the right tonsillar biopsy exhibited a few intracellular oval and elongated yeast-like organisms with some central transverse septum seen, $\mathbf{b}$ they subsequently grew a few mold colonies with the typical diffusible red-colored pigment on fungal cultures, $\mathbf{c}$ the lactophenol cotton blue microscopic examination demonstrated hyaline septate molds, with branched and non-branched conidiophores consisting of brush-like phialides with long chains of round and elliptical conidia

infected adults and children [9-13]. A previous cohort study from Thailand reported that 22 from 34 non-HIV infected cases with T. marneffei infections had no previously known underlying diseases and no apparent immunodeficiencies [11]. Of those 22 cases, blood samples from 9 cases were tested for immunological studies, and all were positive for anti-IFNy autoantibodies by ELISA. According to the study, the anti-IFNy autoantibody may be a newly associated risk factor for T. marneffei infection in non-HIV infected individuals [11]. Anti-IFNy autoantibody is an acquired adult onset immunodeficient condition and its pathophysiology has not yet been clearly described. We still do not know how the autoantibodies are acquired, where from, and why this immunodeficient condition is usually found in adulthood, particularly in Asian populations. Some specific HLA classes, such as HLA-DRB1, and HLA-DQB1 commonly discovered in Asian populations were proposed to be associated with this condition $[14,15]$. Clinical infections of patients with anti-IFNy autoantibodies are usually disseminated diseases caused by opportunistic pathogens, such as non-tuberculous mycobacteria, particularly rapidly growing mycobacteria, Salmonella non-Typhi, Cryptococcus, Histoplasma, Talaromyces, and the VaricellaZoster virus [16, 17]. Similar to this case report, more than half of patients developed relapsed infection from a prior infected organism or recurrent infection from a new opportunistic organism despite receiving long-term antimicrobial treatment [17].

T. marneffei infection in both HIV-infected and nonHIV infected individuals usually manifests as fungemia and disseminated disease to various organs $[11,13,18]$. This case report presented with a subacute onset of oropharyngo-laryngitis caused by $T$. marneffei. $T$. marneffei oro-pharyngo-laryngitis is a rare and atypical presentation of talaromycosis. Previous case reports, including the present case, are summarized in Table $1[6-8,19-21]$. Most of the case reports, including the present case, had underlying immunodeficiencies as predisposing factors. In HIV-infected patients with low $\mathrm{CD}_{4} \mathrm{~T}$ cell counts, T. marneffei oro-pharyngo-laryngitis may present as a part of disseminated talaromycosis. Several case reports demonstrated that oro-pharyngo-laryngitis coincided with systemic involvements, such as multiple skin lesions, lymphadenopthy, and hepatosplenomegaly $[6,9,21]$. This infection presented as subacute or chronic painful papular or ulcerative lesions localized to the oropharyngeal area or progressed to involve the laryngeal area, and sometimes it would not be recognized by the clinician. Presenting symptoms vary based on the area of mucosal involvement, such as painful 
Table 1 A summary of case reports of Talaromyces marneffei oro-pharyngo-laryngitis

\begin{tabular}{|c|c|c|c|c|c|c|c|}
\hline $\begin{array}{l}\text { Country, no. of } \\
\text { case (Year) }\end{array}$ & $\begin{array}{l}\text { Age (yrs.)/ } \\
\text { Sex }\end{array}$ & $\begin{array}{l}\text { Predisposing } \\
\text { conditions }\end{array}$ & $\begin{array}{l}\text { Duration of } \\
\text { symptoms }\end{array}$ & Clinical manifestations & Diagnosis & Treatments & Outcomes \\
\hline $\begin{array}{l}\text { Thailand, } 2 \\
\text { (1997) [19] }\end{array}$ & $\begin{array}{l}29 / \mathrm{F} \\
\mathrm{na} / \mathrm{F}\end{array}$ & HIV infection & na & $\begin{array}{l}\text { Painful oral papules and skin papules (1); } \\
\text { Oral ulcerations (1) }\end{array}$ & $\begin{array}{l}\text { Tissue culture, } \\
\text { histopathology }\end{array}$ & na & na \\
\hline $\begin{array}{l}\text { Thailand, } 1 \\
\text { (2000) [8] }\end{array}$ & $25 / F$ & HIV infection & 3 months & Sore throat, multiple oral papules & $\begin{array}{l}\text { Microscopic } \\
\text { exam, tissue } \\
\text { culture }\end{array}$ & Oral KET, ART & Cure \\
\hline $\begin{array}{l}\text { Hong Kong, } 1 \\
\text { (2001) [7] }\end{array}$ & $63 / M$ & HIV infection & 2 months & Painful multiple oral ulcerations & $\begin{array}{l}\text { Tissue, urine } \\
\text { and blood } \\
\text { cultures, } \\
\text { histopathology }\end{array}$ & $\begin{array}{l}\text { IV AMB, then } \\
\text { oral ITRA, ART }\end{array}$ & Cure \\
\hline $\begin{array}{l}\text { China, } 1 \\
\text { (2012) [20] }\end{array}$ & $39 / M$ & None & 4 months & $\begin{array}{l}\text { Chronic painful granuloma like oral } \\
\text { ulceration }\end{array}$ & $\begin{array}{l}\text { Histopathology, } \\
\text { molecular assay, } \\
\text { electron } \\
\text { microscopy }\end{array}$ & Oral ITRA & Cure \\
\hline $\begin{array}{l}\text { India, } 1 \\
\text { (2017) [21] }\end{array}$ & $33 / M$ & HIV infection & 2 months & $\begin{array}{l}\text { Fever, hoarseness, odynophagia, multiple } \\
\text { skin papules }\end{array}$ & $\begin{array}{l}\text { Tissue culture, } \\
\text { histopathology }\end{array}$ & $\begin{array}{l}\text { IV AMB, then } \\
\text { oral ITRA, ART }\end{array}$ & Cure \\
\hline $\begin{array}{l}\text { China, } 7 \\
\text { (2017) [6] }\end{array}$ & $\begin{array}{l}\text { Median } \\
34 / \mathrm{M}(7)\end{array}$ & $\begin{array}{l}\text { HIV infection } \\
\text { (7) }\end{array}$ & na & $\begin{array}{l}\text { Fever (7), sore throat ( } 7) \text {, regional } \\
\text { lymphadenopathy }(7) \text {, mucosal ulceration } \\
\text { (6), skin lesions (5), hepatosplenomegaly (5), } \\
\text { hoarseness (4), local mass (4) }\end{array}$ & $\begin{array}{l}\text { Tissue culture, } \\
\text { blood culture, } \\
\text { histopathology }\end{array}$ & $\begin{array}{l}\text { IV AMB, then } \\
\text { oral antifungals } \\
\text { (FLU, ITRA) (5), } \\
\text { ART (7) }\end{array}$ & $\begin{array}{l}\text { Dead (3), } \\
\text { improved } \\
(4)\end{array}$ \\
\hline $\begin{array}{l}\text { The present } \\
\text { case }\end{array}$ & $52 / F$ & $\begin{array}{l}\text { Anti-IFNy } \\
\text { autoantibodies }\end{array}$ & 3 weeks & Fever, sore throat, hoarseness, odynophagia & $\begin{array}{l}\text { Microscopic } \\
\text { exam, tissue } \\
\text { culture, } \\
\text { histopathology }\end{array}$ & $\begin{array}{l}\text { IV AMB, then } \\
\text { oral ITRA }\end{array}$ & Cure \\
\hline
\end{tabular}

$A B D$ amphotericin B deoxycholate, Anti-IFN $\gamma$ autoantibodies anti-interferon-gamma autoantibodies, ART antiretroviral therapy, $F$ female, FLU fluconazole, HIV human immunodeficiency virus, ITRA itraconazole, $I V$ intravenous, KET ketoconazole, $M$ male, na not available, yrs. years

oropharyngeal lesions, odynophagia, and hoarseness. However, painful oropharyngeal lesions in HIV-infected individuals have several etiologies, such as aphthous ulceration, herpes simplex infection, erythema multiforme, lymphoma, and histoplasmosis $[19,22]$. Thus, the diagnosis of T. marneffei oro-pharyngo-laryngitis requires tissue microscopic examination and a histopathological finding of spherical, oval, and elongated yeast cells with clear central transverse septations, according to the case reports in Table 1. However, the morphological identification of T. marneffei from a tissue section is not specific because its morphology is occasionally identical to Histoplasma capsulatum and some Candida spp., so tissue fungal culture and isolation are warranted for confirmed diagnosis. The present case was undergoing tonsillar biopsy for microbiological diagnosis very early because recurrent mycobacterial infection and invasive mycoses were highly suspected. In this case, microscopic examination with tonsillar biopsy Gram stain could provide a presumptive diagnosis of talaromycosis (Fig. 2a), and later the tissue fungal culture showed characteristic colonies of T. marneffei (Fig. 2b). A previous study demonstrated an early microscopic examination of the sample could give a presumptive diagnosis before the fungal isolation in approximately $60 \%$ of cases [23]. In cases of disseminated infection listed in Table 1, T. marneffei were also isolated from blood and urine cultures $[6,7]$. The present case was probably not the disseminated infection because the clinical findings showed no evidence of distant organ involvement, including blood culture negative for the fungal isolate. However, the route of T. marneffei oro-pharyngolaryngitis remains unclear, though inhalation or ingestion of contaminated fungal spores may likely be the route of infection. The oropharynx and tonsil are the primary sites for fungal inoculation following inhalation and ingestion. Partial immunity and more inflammatory response to the fungal organism could explain the shorter onset of the patient's symptoms compared to several reported cases.

A treatment regimen of talaromycosis prefers initial induction with a systemic antifungal agent, particularly intravenous amphotericin B for a few weeks, followed by maintenance oral antifungal therapy, particularly itraconazole, and subsequently a continuation of secondary prophylaxis for several weeks [24]. The treatment regimen is generally applied for HIV-infected or immunodeficient persons who have frequently presented with disseminated infection. For T. marneffei oro-pharyngolaryngitis, the treatment regimen has not yet been clearly defined, but it should be based on severity and host immune status. An oral antifungal therapy alone would be appropriate for a localized infection similar to the previous reports $[8,18]$, whereas an initial intravenous antifungal therapy should be used for severe or extensive $T$. marneffei infection and for an infection occurring in immunodeficient persons. Most of the previous cases, including the present case, did respond well to the antifungal therapy, although 2 cases died from delayed 
antifungal therapy and 1 died from unresponsive treatment. Treatment outcomes are also based on host immunity. In HIV-infected persons, antiretroviral treatment should be started early to raise the $\mathrm{CD}_{4} \mathrm{~T}$ cell counts when diagnosing $T$. marneffei infection $[6,18,24]$. Secondary antifungal prophylaxis can be discontinued when the numbers from the $\mathrm{CD} 4 \mathrm{~T}$ cell counts are increasing sufficiently regarding the recommendation [24]. However, in patients with anti-IFNy autoantibodies, a standard antifungal treatment regimen, including long-term antifungal therapy, has still not been established. The author considered a continuation of long-term antifungal prophylaxis to prevent relapse of the T. marneffei infection in this case. In conclusion, in patients with anti-IFN-gamma autoantibodies, T. marneffei can rarely cause a local infection involving the pharynx and larynx. Fungal culture, microscopic examination, and histopathological study are warranted for the diagnosis of $T$. marneffei oro-pharyngolaryngitis. A long-term antifungal therapy was required to successfully treat this infection.

\section{Abbreviations}

ABD: amphotericin B deoxycholate; Anti-IFNy autoantibodies: anti-interferongamma autoantibodies; ART: antiretroviral therapy; F: female;

FLU: fluconazole; HIV: human immunodeficiency virus; ITRA: itraconazole;

IV: intravenous; KET: ketoconazole; M: male; na: not available; yrs.: years

\section{Acknowledgements}

The authors would like to acknowledge the staff of Mycology Laboratory Unit, Department of Microbiology for providing the microbiological data.

\section{Authors' contributions}

TW and AJ carried out the clinical follow up and draft the manuscript. PC supervised mycology laboratory, antifungal susceptibility testing, fungal identification, and molecular typing. All authors read and approved the manuscript.

\section{Funding}

Not applicable.

\section{Availability of data and materials}

All data and materials of this article are included in the manuscript and thus available to the reader.

\section{Ethics approval and consent to participate}

This case report has been granted an exemption from requiring ethics approval according to the Scientific Ethics Committee of the Siriraj Institutional Review Board (SIRB), Faculty of Medicine Siriraj Hospital, Mahidol University.

\section{Consent for publication}

Written informed consent was obtained from the participating patient for publication of this case report and any accompanying images. A copy of the written consent is available for review upon request.

\section{Competing interests}

The authors declare that they have no competing interests.

\section{Author details}

'Division of Infectious Diseases and Tropical Medicine, Department of Medicine, Faculty of Medicine Siriraj Hospital, Mahidol University, 2 Wanglang Road, Bangkoknoi, Bangkok 10700, Thailand. 'Department of Microbiology, Faculty of Medicine Siriraj Hospital, Mahidol University, Bangkok, Thailand.
Received: 10 October 2019 Accepted: 22 November 2019

Published online: 05 December 2019

\section{References}

1. Vanittanakom N, Cooper CR Jr, Fisher MC, Sirisanthana T. Penicillium marneffei infection and recent advances in the epidemiology and molecular biology aspects. Clin Microbiol Rev. 2006;19(1):95-110.

2. Wong SS, Siau H, Yuen KY. Penicilliosis marneffei- west meets east. J Med Microbiol. 1999:48(11):973-5.

3. Hu Y, Zhang J, Li X, Yang Y, Zhang Y, Ma J, Xi L. Penicillium marneffei infection: an emerging disease in mainland China. Mycopathologia. 2013; 175(1-2):57-67.

4. Chan JF, Lau SK, Yuen KY, Woo PC. Talaromyces (Penicillium) marneffei infection in non-HIV-infected patients. Emerg Microbes Infect. 2016;5:e19.

5. Pruetpongpun N, Khawcharoenporn T, Damronglerd P, Suthiwartnarueput W, Apisarnthanarak A, Rujanavej S, Suwantarat N. Disseminated Talaromyces marneffei and Mycobacterium abscessus in a patient with anti-interferon- $\gamma$ autoantibodies. Open Forum Infect Dis. 2016;3(2):ofw093.

6. Qiu Y, Tang Y, Zhang J, Yi X, Zhong X, Liu G, Xu H, Lei Y. A retrospective analysis of seven patients with acquired immunodeficiency syndrome and pharyngeal and/or laryngeal Talaromyces marneffei infection. Clin Otolaryngol. 2017;42(5):1061-6.

7. Tong AC, Wong M, Smith NJ. Penicillium marneffei infection presenting as oral ulcerations in a patient infected with human immunodeficiency virus. $J$ Oral Maxillofac Surg. 2001;59(8):953-6.

8. Kantipong P, Walsh DS. Oral penicilliosis in a patient with human immunodeficiency virus in northern Thailand. Int J Dermatol. 2000;39(12): 926-8.

9. Zhang JQ, Yang ML, Zhong XN, He ZY, Liu GN, Deng JM, Li MH. A comparative analysis of the clinical and laboratory characteristics in disseminated penicilliosis marneffei in patients with and without human immunodeficiency virus infection. Zhonghua Jie He He Hu Xi Za Zhi. 2008; 31(10):740-6.

10. Lee PP, Chan KW, Lee TL, Ho MH, Chen XY, Li CH, Chu KM, Zeng HS, Lau YL. Penicilliosis in children without HIV infection: are they immunodeficient? Clin Infect Dis. 2012;54:e8-e19.

11. Kawila R, Chaiwarith R, Supparatpinyo K. Clinical and laboratory characteristics of penicilliosis marneffei among patients with and without HIV infection in northern Thailand: a retrospective study. BMC Infect Dis. 2013;13:464

12. Zeng W, Qiu Y, Lu D, Zhang J, Zhong X, Liu G. A retrospective analysis of 7 human immunodeficiency virus-negative infants infected by Penicillium marneffei. Medicine (Baltimore). 2015;94:e1439.

13. Qiu Y, Liao H, Zhang J, Zhong X, Tan C, Lu D. Differences in clinical characteristics and prognosis of penicilliosis among HIV-negative patients with or without underlying disease in southern China: a retrospective study. BMC Infect Dis. 2015;15:525.

14. Pithukpakorn M, Roothumnong E, Angkasekwinai N, Suktitipat B, Assawamakin A, Luangwedchakarn V, et al. HLA-DRB1 and HLA-DQB1 are associated with adult-onset immunodeficiency with acquired antiinterferon-gamma autoantibodies. PLoS One. 2015;10(5):e0128481.

15. Chi CY, Chu CC, Liu JP, Lin CH, Ho MW, Lo WJ, et al. Anti-IFN-gamma autoantibodies in adults with disseminated nontuberculous mycobacterial infections are associated with HLA-DRB1*16:02 and HLA-DQB1*05:02 and the reactivation of latent varicella-zoster virus infection. Blood. 2013;121(8): 1357-66.

16. Browne SK, Burbelo PD, Chetchotisakd P, Suputtamongkol Y, Kiertiburanakul $\mathrm{S}$, Shaw PA, et al. Adult-onset immunodeficiency in Thailand and Taiwan. N Engl J Med. 2012;367:725-34.

17. Angkasekwinai N, Suputtamongkol Y, Phoompoung P, Pithukpakorn M, Wongswat $\mathrm{E}$, Umrod $\mathrm{P}$, et al. Clinical outcome and laboratory markers for predicting disease activity in patients with disseminated opportunistic infections associated with anti-interferon- $\gamma$ autoantibodies. PLoS One. 2019; 14(4):e0215581.

18. Sirisanthana T, Supparatpinyo K. Epidemiology and management of penicilliosis in human immunodeficiency virus-infected patients. Int J Infect Dis. 1998;3(1):48-53.

19. Nittayananta W, Chungpanich S. Oral lesions in a group of Thai people with AIDS. Oral Dis. 1997;3(Suppl 1):S41-5.

20. Hua X, Zhang $R$, Yang $H$, Lei S, Zhang Y, Ran Y. Primary oral Penicillium marneffei infection diagnosed by PCR-based molecular identification and 
transmission electron microscopic observation from formalin-fixed paraffinembedded tissues. Med Mycol Case Rep. 2012;2:15-8.

21. Lalnunhlua HC, Devi SB, Chanu KJ, Singh KB. Hoarseness due to penicillium marneffei infection- an unsual presentation. Int J Med Dent Sci. 2017;6(1): $1426-9$.

22. Batavia AS, Secours R, Espinosa P, Jean Juste MA, Severe P, Pape JW, et al. Diagnosis of HIV-associated oral lesions in relation to early versus delayed antiretroviral therapy: results from the CIPRA HT001 trial. PLoS One. 2016; 11(3):e0150656.

23. Supparatpinyo K, Khamwan C, Baosoung V, Nelson KE, Sirisanthana T. Disseminated Penicillium marneffei infection in Southeast Asia. Lancet. 1994; 344:110-3.

24. Masur H, Brooks JT, Benson CA, Holmes KK, Pau AK, Kaplan JE, National Institutes of Health, Centers for Disease Control and Prevention, HIV Medicine Association of the Infectious Diseases Society of America. Prevention and treatment of opportunistic infections in HIV-infected adults and adolescents: updated guidelines from the Centers for Disease Control and Prevention, National Institutes of Health, and HIV Medicine Association of the Infectious Diseases Society of America. Clin Infect Dis. 2014;58(9): 1308-11.

\section{Publisher's Note}

Springer Nature remains neutral with regard to jurisdictional claims in published maps and institutional affiliations.

Ready to submit your research? Choose BMC and benefit from:

- fast, convenient online submission

- thorough peer review by experienced researchers in your field

- rapid publication on acceptance

- support for research data, including large and complex data types

- gold Open Access which fosters wider collaboration and increased citations

- maximum visibility for your research: over $100 \mathrm{M}$ website views per year

At BMC, research is always in progress.

Learn more biomedcentral.com/submissions 